\title{
The Risk and Vulnerability Assessment Centre at the University of Limpopo: Generating New Research Possibilities within Southern African-Nordic Centre
}

\section{Rachmond Howard}

Jesika Singh

Research Development and Administration, University of Limpopo, South Africa

Kola O. Odeku

Faculty of Management and Law, School of Law, University of Limpopo, South Africa

Doi:10.5901/mjss.2014.v5n3p684

\begin{abstract}
Multiple stresses such as poor service delivery; poverty; inadequate supply of infrastructure in water and energy; complex disease burden and food crises are rampant and prevalent in the rural poor areas making them to be vulnerable. The impact of climate change and variability is aggravating the already dicey situation. The Department of Science and Technology in South Africa, cognisant of this scientific prediction, responded by funding the establishment of Risk and Vulnerability Assessment Centres at rural universities in South Africa. The core mandate of the centres is to supply quality research data on rural areas on a number of critical indicators identified in the South African Risk and Vulnerability Assessment Atlas. In addition, these centres are expected to provide excellent tertiary education in spatial analysis and modelling applied to the environment, economic, social and health sectors. Data and information from the Atlas will be used by local authorities for improved planning, decision-making and appropriate intervention strategies at the target sites. This paper presents an overview of the centre at the University of Limpopo and explores some of the research areas in which the University of Limpopo can collaborate with other members in the Southern African-Nordic Centre Partnership
\end{abstract}

Keywords: Climate change, Risk and vulnerability Atlas, Research, Rural Areas, Limpopo

\section{Introduction}

Partnership and collaboration are parts of the approaches that are being used these days by researchers and scholars to investigate and offer solutions to numerous global climate change challenges and the risks and vulnerability they present (Fraser et al., 2011). Against this backdrop, "the Southern African-Nordic Centre (SANORD) is a partnership of higher education institutions from all the Nordic countries and southern Africa. Its primary aim is to promote multilateral research cooperation on matters of importance on the development of both regions. SANORD is committed to advancing strategic, multilateral academic collaboration between institutions in the two regions, seeking to address new local and global challenges of innovation and development" (SANROD, 2013).

Risk and vulnerability are closely linked together, especially when discussing issues relating to global climate change and how to mitigate and adapt to the risks posed by the unstable bizarre weather events. Changes in the climate, being emerging issues, they present various challenges, Brooks (2003) writes that "the study of the vulnerability of human and natural systems to climate change and variability, and of their ability to adapt to changes in climate hazards, is a relatively new field of research that brings together experts from a wide range of fields, including climate science, development studies, disaster management, health, social science, policy development and economics, to name but a few areas. Researchers from these fields brought their own conceptual models to the study of vulnerability and adaptation, models which often address similar problems and processes using different languages. Somehow researchers from all these different backgrounds must develop a common language so that vulnerability and adaptation research can move forward in a way that integrate these different traditions in a coherent yet flexible fashion, allowing researchers to assess vulnerability and the potential for adaptation in a wide variety of different contexts, and in a manner that is transparent to their colleagues."

Weather connotes the day-to-day atmospheric or meteorological conditions (temperature, moisture or humidity, 
cloudiness or sun-shine, wind velocity and barometric pressure) at a specific location and moment in time (Eagan and Schofield, 1997). Karl and Trenberth (2003) indicated that "modern climate change is dominated by human influences, which are now large enough to exceed the bounds of natural variability. The main source of global climate change is human-induced changes in atmospheric composition. These perturbations primarily result from emissions associated with energy use, but on local and regional scales, urbanization and land use changes are also important. Although there has been progress in monitoring and understanding climate change, there remain many scientific, technical, and institutional impediments to precisely plan for, adapt to, and mitigate the effects of climate change. There is still considerable uncertainty about the rates of change that can be expected, but it is clear that these changes will be increasingly manifested in important and tangible ways, such as changes in extremes of temperature and precipitation, decreases in seasonal and perennial snow and ice extent, and sea level rise. Anthropogenic climate change is now likely to continue for many centuries. We are venturing into the unknown with climate, and its associated impacts could be quite disruptive."

Davies (2011:8) describes weather as "the set of meteorological phenomena we experience on a daily basis. Weather conditions might be sunny and hot, or cloudy and rainy. We expect changes in weather to occur from day to day."

While weather is driven by the energy of the sun and the rotation of the earth, climate is the long-term average of weather conditions of a specific location (Flannery, 2006). Scientific reports and scholarly studies have revealed that the earth's climate that has fluctuated within reasonable limits for life on earth is changing for the worst (Stern, 2007).

Davis (2011:8) explains the meaning of climate as "the average of individual weather states, taken over sufficiently long periods of time. While weather impacts our daily lives, climate influences our decisions about where to live, and where and how to grow food. In this way, it directly influences how societies and economies develop and flourish. Changes in climate are associated with more fundamental changes to the global climate system, involving interactions and feedbacks between the atmosphere, the oceans, land and ice surfaces and all living things (the biosphere)."

The reality is that the changes in the weather and climate are emerging as new challenges and humans are expected to adapt because the changes will be around for years to come unless steps are taken to mitigate and control causes of global climate change (Barnett et al., 2005).

Barnett et al. (2005) explained the causes of global climate change and provided an insight into the consequences by pointing out that "all currently available climate models predict a near-surface warming trend under the influence of rising levels of greenhouse gases in the atmosphere. In addition to the direct effects on climate-for example, on the frequency of heat waves-this increase in surface temperatures has important consequences for the hydrological cycle, particularly in regions where water supply is currently dominated by melting snow or ice. In a warmer world, less winter precipitation falls as snow and the melting of winter snow occurs earlier in spring. Even without any changes in precipitation intensity, both of these effects lead to a shift in peak river runoff to winter and early spring, away from summer and autumn when demand is highest. Where storage capacities are not sufficient, much of the winter runoff will immediately be lost to the oceans. With more than one-sixth of the Earth's population relying on glaciers and seasonal snow packs for their water supply, the consequences of these hydrological changes for future water availability-predicted with high confidence and already diagnosed in some regions-are likely to be severe."

The primary effects of climate change will be on resources such as "water resources; ecological and biodiversity systems; the polar ice; available land for food production, human settlement and commercial forestry; human, animal and plant diseases and pests; oceans systems and marine life" (Spellerberg, 2005). Humans depend on these resources for livelihood and survival. To this end, if these resources become extinct within a geographical area due to the impact of climate change, this might lead to people migrating to other areas thereby causing distortion in settlement patterns (Eldredge, 2000). The consequences will have huge impact hence the need for intervention in order to disable the predicted catastrophic calamities (Cuff, 2001).

The Southern African Developing Countries (SADC) adoptede the Intergovernmental Panel on Climate Change (IPPC, 2007) conceptual framework and models for climate change risk and vulnerability assessment (Davis, 2011). This was done realising that the Southern Africa "is likely to be significantly impacted by future climate change with the latest climate change projections for the region indicating that both temperature and evapotranspiration are likely to increase into the 21st century. Climate change is likely to alter the magnitude, timing, and distribution of storms that will produce flood events as well as the increase infrequency and intensity of drought events. Southern Africa has existing critical vulnerabilities that may exacerbate the effects of such climatic change in most sectors due to the direct dependence on the natural environment for livelihood support, amongst other factors. Understanding these climatic changes and their possible impacts on society is thus essential in critical sectors in southern Africa in order to improve strategic adaptation 
response" (Davis, 2011).

More importantly is the measures taken in SADC to sensitise and encourage members to "improve planning under climate change and for access to climate information as well as mitigation/air quality information. SADC member states have demonstrated increased access to climate change information (projections and updated impact studies) as a priority in undertaking response and adaptation as part of in-country gap analysis around climate change" (Davis, 2011).

Vulnerability as a concept has found a place in the climate change discourse among scholars and researchers who are studying the impacts of climate change on humans and ecosystems. Because of the unique space occupied by this concept in providing solution to the devastating impact of climate change, Hans-Martin and Klein (2006) said "vulnerability is an emerging concept for climate science and policy. Over the past decade, efforts to assess vulnerability to climate change triggered a process of theory development and assessment practice, which is reflected in the reports of the Intergovernmental Panel on Climate Change (IPCC). This evolution is characterized by the progressive inclusion of non-climatic determinants of vulnerability to climate change, including adaptive capacity, and the shift from estimating expected damages to attempting to reduce them. We hope that this paper improves the understanding of the main approaches to climate change vulnerability assessment and their evolution, not only within the climate change community but also among researchers from other scientific communities, who are sometimes puzzled by the unfamiliar use of technical terms in the context of climate change."

Vulnerability to climate change is defined as "the degree to which a system is susceptible to, and unable to cope with, adverse effects of climate change, including climate variability and extremes" (Shukla, 2003). "Vulnerability is a function of the character, magnitude, and rate of climate change and variation to which a system is exposed, its sensitivity, and its adaptive capacity" (Hans-Martin, 2007). The assessment of vulnerability includes a measure of exposure to risk factors and sensitivity to risk factors. Together these constitute potential impact of such risks, and the capacity to manage and respond to those risks (Davies et al., 2010).

The African continent has been highlighted as particularly vulnerable to global change, especially to climaterelated stressors since a large portion of people on the continent are experiencing multiple development stresses; notably poor service delivery, low quality of live, poverty, poor and fragile infrastructure, inadequate supply and infrastructure of water and energy, complex disease burden and food crises (Black et al., 2008). Environmental change, drought and land degradation add to this vulnerability (Turner et al., 2007). Turner et al. (2007) point out that "as with estimates of land transformations and alterations, there is little doubt that human activity usurps a large proportion of terrestrial net primary productivity, but the uncertainty in the estimates remains large."

According to Thomas et al. (2008), the poor in rural areas will be hardest hit and will suffer a lot. Agricultural production remains the main sources of livelihood for rural communities in Africa, providing employment to more than 60 percent of the population and contributing to about $30 \%$ of the gross domestic product (Diao et al., 2007). Scientific studies have shown that agriculture is inherently sensitive to climate conditions and is one of the most vulnerable sectors to the risks and impact of climate change (Kelly and Adger, 2000). Hence, an adverse effect on agriculture due to climate change would drastically worsen the livelihood of rural people (McGuigan et al., 2002). Most of the SADC region is expected to become warmer and drier with climate change (Nhemachena and Hassan, 2007). This will certainly impact negatively on food production and the livelihood of the poor since the SADC region is over-reliant on rain-fed agriculture for food production and it has a large poor rural population, relatively undiversified economies and poorly developed infrastructure (Adetula, 2011).

The global community, at the Conference of the parties (COP 17) meeting of 2011 confirmed the importance of developing comprehensive responses to the problems of climate change (Chevallier, 2011). This entails the establishment of capacity and systems for monitoring, predicting and identifying vulnerability hotspots and then developing and implementing effective mitigation and adaptation measures (Roberts, 2008). In response to the South African situation, the Department of Science and Technology funded several initiatives including the establishment of Regional Risk and Vulnerability Assessment Centres (RVAC) at rural universities in South Africa (Vogel et al., 2010).

While the central focus of this paper is to present an overview of the RVAC at the University of Limpopo and possible areas in which RVAC can collaborate with other members in the SANORD Partnership, it also provides the overarching rational and context in which such centres are expected to function and contribute meaningfully on how to assist the rural poor and farmers to adapt to the climatic risks. Other important activities within RVAC especially regarding research and demonstration are also highlighted and analysed. 


\section{The Rational for Establishing Risk and Vulnerability Assessment Centres}

In South Africa, government and various departments are taking steps and measures that will assist the poor community in coping with climatic risks and reduce their vulnerability ( Bryan et al., 2009). To this end, the Department of Science and Technology (DST) in South Africa has come up with a Ten-Year Innovation Plan (2008-2018) and the focus will be to use contemporary science and technology to address major challenges of global climate change and the attendant risks and vulnerability (Bryan et al., 2009). Therefore, Climate change problems are addressed as part of three Grand Challenges Programmes namely; Space Science and Technology, Global Change, and Human and Social Dynamics (Kaplan, 2008). "Part of the Space Science and Technology Grand Challenge aims to improve space observation technology (such as satellite and telescopic technologies) which will permit better monitoring of climate change and its impact on terrestrial systems (example, ecological systems and biodiversity, water, disasters, settlement patterns and development, etc.) with a view to use such data to better manage natural resources and respond to climate change and disasters" (Beer and McCracken, 2012). "A second major programme under this Grand Challenges is to mitigate against climate change by providing energy security through the development of clean coal technologies and alternative environmentally friendly renewable and sustainable energy" (Kaygusuz, 2009). Under its Global Change Grand Challenge, South Africa seeks the following outcomes, to: "establish an internationally recognised science centre of excellence with climate change research and modelling capabilities benefiting the entire continent; establish an internationally recognised centre of excellence focused on the Southern Oceans and its contribution to global change processes; strengthen research and global monitoring capabilities on Marion Island, Antarctica and the Southern Oceans in partnership with other nations; generate robust regional scenarios for the rate and impact of climate change and extreme weather conditions for South Africa and the continent; and initiate climate change mitigate and adaptation actions."

Under the Human and Social Dynamics Grand Challenges, especially in relation to global change, South Africa seeks to: "enhance its research and modelling capabilities to anticipate the complex consequences of change and its impact on the dynamics of individual and social behaviour (decision-making, risk-taking and adaptation) at all levels; have better understanding of the cognitive and social structures which create and define change; and help people and organisations better manage profound or rapid change."

It is pertinent to point out that South Africa climate change is embedded within a much broader context of societal change influenced by other non-climate change factors (Adger et al., 2002). Various initiatives have been launched to implement actions based on these Grand Challenges. South Africa has launched the South African Risk and Vulnerability Atlas (SARVA) with the main aim of "assisting decision-makers in identifying risk, planning and mapping a future, which would be more resilient to the changing climatic conditions in the country" (Van Der Merwe, 2010). The atlas will be a platform to drive research and disseminate research information from research community on most of the pressing vulnerability and risks areas and collect data to be used for analysis and possible adaptation and mitigation interventions (Seely et al., 2008). The scope therefore extends to and covers areas such as the impact of climate change on water, agriculture, human health, coastal zones, biodiversity, commercial forestry and land use (Van Der Merwe, 2010). For effective and reliable data collection, the Atlas needs to be updated regularly based on the latest data and findings. To this end, capacity building for decision-makers in order to grasp the scientific readings and understanding of the Atlas is essential for effective use of the data to collect results and findings that will be used for policy-making and planning for appropriate action (Kraak and Ormeling, 2011). In recognition of the unique challenges faced by the most vulnerable people in rural areas, the DST funded the establishment of regional Risk and Vulnerability Assessment Centres (RVAC), strategically located at rural based universities such as University of Limpopo, University of Venda, Walter Sisulu University, University of Fort Hare and the University of Zululand. These universities are located in predominantly rural environments in the Limpopo, Eastern Cape, and KwaZulu Natal Provinces. The aim of establishing the centres is to assist rural based universities to enhance their capacities and capabilities by conducting research and collecting data in the area of climate change and environmental changes and use them to assist the local communities and others to respond to climate changes related challenges (van Aalst et al., 2008). SARVA was chosen for funding because much of the data is spatial, and needs to be in order to satisfy the requirements of local adaptation, particularly for ease of use in solving local risks and vulnerability facing the rural poor (O'Keeffe et al., 2009).

These centres will engage in a wide range of research activities and issues relating to mitigation and adaptation to climate change under the stewardship of local university experts in identifying risks and vulnerability. This will result in useful and meaningful solutions to various activities and evaluations and assessments of how the data collected and findings are having impact on the social economic livelihoods of the rural people and more importantly, provide holistic 
assistance to the local and rural community based on what the Atlas was established to do and achieve. Scientifically, the centre will "develop appropriate technologies and assessment tools for better monitoring of change, risks and vulnerability, develop models to address issues associated with Global Change at provincial and national levels as well as for the SADC region in particular and the African continent in general. They will also map identify environmental and other risk factors through the use of satellite imagery and Geographic Information System (GIS), develop sustainability assessment methodologies relevant for the rural context, develop technological innovations for mitigation and adaptation to climate change" (DST, 2010).

\section{The Limpopo Regional Risk and Vulnerability Assessment Centre (RVAC) and Possible Areas for Collaborations}

In 2010, the University of Limpopo leveraged its capacity in the Vlaamse- Interuniversitaire Raad (VLIR) - Institutional Co-operation (IUC) Programme and collaborations with KLIMOS, Applied Centre for Climate and Earth System Studies (ACCESS), the Limpopo Government and the Centre for Strategic and Industrial Research (CSIR) and successfully bided and won the right to establish RVAC at the University. The research programme with the theme 'Human Wellness in the Context of Global Change - Finding Solutions for Rural Africa is under the auspices of the UL-VLIR-IUC and a consortium of Belgium universities namely; (Haselt, Antwerp, Gent and Vrije). The Programme has five cluster areas with varying number of projects associated with the clusters which is detailed thus, "Cluster 1 consists of Cross cutting issues like centre for spatial analysis and modelling, KLIMOS, Data Mining and Management and analysis, GIS, Risk and Vulnerability and other UL provincial research activities. Cluster 2 is Competent Communities which consists of energising competent communities, multiple literacies (Increase capacity for multiple literacies knowledge development, which includes language literacy, science literacy, multi modal texts (visual, spatial, dramatic arts), disease management: rural areas, UL's community engagement (Create a model to enable a community to become a responsive, competent community that can improve their developmental potentials in the context of global change). The third cluster is Water and consists of subprojects: fish health, water quality, Olfants river forum (Determine the impact of water variability, water pollution and contaminated fish on human health and aquatic ecosystem in general. The Olifants river to be used as a model). The fourth cluster is Food security which looks at livestock, indigenous crops, bio-technology, and agribusiness (Improve food security in rural areas through developingof UL's capacity in enhancing agricultural productivity, focusing on; improvement of indigenous chicken breeds, introducing more drought resistant indigenous crop varieties, biotechnology related to aforementioned, improved production and marketing methods, integration of food security issues in development interventions through sustainability assessment. The population has developed significant levels of chronic disease risk factors, despite living in an area under poor socio-economic circumstances). The Fifth cluster is Public health, research on infectious diseases (Developing effective intervention models for Health problems and health promotion among health care workers Social aspects of HIVIAIDS in children)."

\section{Collaborations}

RVAC's research activities are transcidisciplinary in nature hence the centre works with virtually all faculties and departments within the university. At the international level, RVAC is currently collaborating with the international and national organisations and is working towards expanding its networks within and outside of African continent.

\subsection{KLIMOS Climate and Development (KLIMOS)}

KLIMOS, is a Flemish interdisciplinary and university research platform working on the integration of climate change and environmental sustainability in development interventions ( Hugé et al. 2011). KLIMOS aim is to "develop a knowledge base on the consequences of climate change (and related environmental issues) in developing countries and to share this knowledge with stakeholders. In particular, KLIMOS studies how energy, food security and forest issues can be integrated in a sustainable way into development; develops environmental sustainability toolkit to support decisionmakers in fostering sustainable development; develops participatory sustainability assessment methodologies and the application of these to establish more resilient and empowered local communities" (Muys, 2013). 


\subsection{Collaborations with provincial departments}

Various government departments like Statistics South Africa, the Department of Agriculture and Rural Development and the Department of Planning are envisaged to be partners with the RVAC. Currently, the Limpopo Economic Development, Environment and Tourism (LEDET) are actively involved with the RVAC. The on-going environmental research at LEDET focuses on three main issues:

\subsubsection{Ecological footprint}

Even though human beings needs natural resources for use as goods and services for example energy for heat and mobility, furniture and paper, food and water, and so on during the processes of productions, to survive a lot of noxious gases and emissions would be released to the environment impacting on the quality of air, fertility of soil, fresh water and so on (Huq and Konate, 2003). By this, nature supplies the needs and also absorbs the waste at the same time. There is therefore a need to balance the tension of living a good life for all and at the same time ensuring capacity of the biosphere to sustain the usage (Moldan et al., 2012). This calls for sustainable development intervention defined as (Wackernagel and Rees, 2013) "improving the quality of life while living within the carrying capacity of supporting ecosystems" (Chambers et al., 2014). A change in attitude and mind-set is also important because the natural resources are finite in the planet's ecological bank account (Cheng-Zhang et al., 2010). "If we continually engaging business as usual by depleting this capital, at a point in time, we will have nothing left to draw upon. Self-restrain is therefore advocated, this implies that human beings should learn to live within nature's interest; sharing the bounty with the tumultuous diversity of other life on this planet" (Chambers et al., 2014). An ecological footprint provides a clear numerical value reflecting the use of resources and allows for concrete measures around environmental management (Moldan et al., 2012). In this regard, steps have been taken to "assess and estimate ecological footprints of individuals and organisations in South Africa" (van Vuuren and Bouwman, 2006).

\subsubsection{Valuation of Natural Resources}

Valuation of living natural resources is a new trend in environmental economics, which allows for monetary value to be assigned to biodiversity systems (Nunes and van den Bergh, 2001). The purpose of this project is to prove that ecosystem services have tangible financial value, which increases over time and should become part of the calculation of the provincial assets that can be channelled towards poverty alleviation and rural development ( Chee, 2004).

\subsubsection{Climate Change}

All efforts should be geared towards being proactive regarding research to address global climate change (Few et al., 2007). Measurement, assessment, monitoring and evaluation play significant role on how to mitigate and adapt to climate change especially on the negative impacts on water security, food security, settlements and infrastructure due to climate change (Smit and Pilifosova, 2003). Data collected will serve as tool to develop a Climate Change Response Strategy for the Province and the rural people. This will encourage prompt dissemination of results, data and information to district and local municipalities and develop the Green Economy Strategy for the Province to mitigate against climate change (Ribeiro et al., 2009).

\subsection{Collaboration with others national partners}

\subsubsection{Applied Centre for Climate and Earth Sciences (ACCESS)}

ACCESS is a "consortium of several agencies, researcher councils, research programmes, universities and research groups who have combined efforts to deliver a range of outputs aligned to DST's Global Change Grand Challenge. It is a platform for an "integrated and end-to-end research and education, services and training outputs and outcomes related to the opportunities and challenges emanating from a varying and changing environment, collectively referred to as Earth Systems Science" (Access, 2014). 


\subsubsection{South African Environmental Observation Network (SAEON)}

SAEON was established in 2002 for purposes of working in "collaboration with government, science institutions and civil society to answer questions about environmental change and the implications for South Africa's life-support systems. SAEON contributes reliable data and information to scientific understanding and management information for the path towards sustainable development through six operational nodes and a network of collaborators performing long-term observations of the national landscape and surrounding oceans." (Pauw, 2011:11). This initiative was started against the backdrop that "the Southern African environment presents a huge challenge and is characterised by high levels of variability and biodiversity (Adger, 2003). Rainfall is important for human survival hence it is a primary driver of the ecosystems, but its high erratic nature and variability limits its usefulness as an indicator of environmental change" (Assessment, 2005). Its erratic nature presents an unpredictable and precarious situation and could complicate situation if the timing is wrong and may impact and distort surface temperature, humidity, soil, slope and vegetation (Midgley et al., 2011). The impacts of these complexities, coupled with differential responses by thousands of species sometimes cause uncertainty about the direction and extent of rainfall-induced change (Vetter, 2009).

Southern Africa's indigenous biodiversity is also hugely impacted and has changed the landscapes and oceans due to the adjoining land uses such as mining, farming, conservation, forestry, urban sprawl, communal resource management, fishing and golf estates (Meffe et al., 2010). Similarly, "time-series data covering the spectrum of spatial scales is essential for reliable data on significant environmental changes, some of which are slow, while others may be sudden. This is because data obtained over short periods and at single locations offer limited value" (Kent, 2011).

Scientific study has shown that the advance of climate change is already being observed but how, when and where it will impact on Southern African society remains uncertain (Tyler et al., 2009). Currently, "rural communities, commonly desperate for resources and information, are particularly vulnerable to climatic variability, which is often aggravated by unsustainable agricultural and fishing practices, not only by those communities themselves, but also by commercial and illicit enterprises (Conway and Barbier, 2013)."

Adaptation intervention is therefore significant and urgently required to bring more certainty to weather predictions about the environment and the changes in the climate ( Mukheibir and Ziervogel, 2007). This will be a useful tool that will enable formulation of adaptive and mitigating management policies and practices, for themes ranging from food production to population health for sustained rural livelihood and alleviation of climate-induced poverty (SAEON, 2009).

According to SAEON's mandate, its responsibilities rest on three mandates: observation of earth systems, data and information storage and dissemination and education. SAEON's flagship programmes are "Tierberg Karoo Research Centre: 20 years of data. This project assembled organised, analysed and archived 2 gigabytes of various long-term datasets (raw data, photographs, publications and so on) as a contribution to SAEON's Node for Arid Lands. Jonkershoek High Altitude Catchment: 60 years of data Continuation of long-term monitoring of climate change. Monitoring climate change is demonstrated by the decline in Mean Annual Precipitation and Runoff' (SAEON, 2009).

SAEON undertakes projects on marine research with the aim of creating "a baseline of scientific information for this large marine ecosystem which can be used to ensure effective environmental governance and collaborative management in order strengthen the scientific understanding of the South West Indian Ocean, a region increasingly recognised for its role in global climate change. This project is significant considering the frightening predictions of climate change, hence the project will provide sustained long-term monitoring and comprehensive baseline data" (Paterson, 2010).

This project, together with others will address identified DST's Global Change Grand Challenge with the main focuses on climate change where South Africa's geographic position enables it to play a leading role in global climate change research and sustainable development. Invariably, the findings and results will serve as major contribution and significantly address the knowledge challenges and gaps that have emerged as part of the Global Change Grand Challenge (Paterson, 2010).

\section{Anticipated Outcomes of the Limpopo RVAC}

At the helm of affairs at the University of Limpopo RVAC is Prof Ayisi who explained according to Ayisi (2012) what the centre would be doing and the expected outcomes thus "the South African Risk and Vulnerability Assessment Centre primarily is an information technology platform, designed to facilitate the uptake of information for use in policy formulation and other relevant applications. RVAC is developing an atlas to assist decision makers in identifying risks to enable planning and mapping a future that will be more resilient to climate change. The centre also works to improve the 
flow of information from researchers to society to bridge the gap between global climate change science and policy" (Ayisi, 2012).

The centre will also work and partner with the local communities in Limpopo Province and engage in participatory sustainability assessments to identify the communities' risks and vulnerabilities and develop and apply appropriate adaptive measures. These will provide useful and meaningful assistance that will alleviate poverty and the plight of the community. The overall goal is therefore to strengthen the resilience of the local communities in Limpopo Province. Furthermore, to strengthen "the scientific knowledge regarding the design, application and policy translation of risk and vulnerability assessments; the linkages between the scientists and local communities through collaboration on case studies, pilot projects and action research; internationalisation of research, delivery of a high level work-ready workforce, relevant new-knowledge generation for the region and further a-field, increased student and publication outputs, staff development, increased career choices and more diversified employability of UL graduates; achievement of aims set by DST for regional RVAC centres; better Regional Planning and Resource Management."

\section{Conclusion}

Research and implementation of the findings of studies are the main tools needed to address the risks and vulnerability emanating from climate change. SANROD in collaboration with the historically rural black universities have intensified their research activities on the evidence based studies in order to fill the seemingly gaps with regard to various challenges being faced by rural people where these universities are located. Undoubtedly, with appropriate support by all the stake and role players, data collected can be used for purposes of monitoring and evaluation of the impact of climate change on whole aspect of the rural dwellers including but not limited to farming, agriculture, food production, water, rainfall drought and so on. The presence of centres is good, but having the centres are not enough, they must be used to perpetrate and promote research activities that will impact positively on the social economic well beings of the people.

\section{Recommendations}

The continuity of the partnership should be the major underpinning of the collaboration. This is highlighted against the backdrop that formidable and useful centres of this nature have collapsed and failed to continue to discharge the functions with which they were set up due to some problems which, if evaluated, have no bearing to the focus of the responsibilities of the centres. Towards this end, experienced, dedicated qualified academic should at all-time be the head of the centres in order to continue to champion research activities. Funding is very important, while the centres are expected to generate funding, the host universities and other collaborators should always release funds as at when due in order not to truncate the noble idea of embarking on and producing meaningful and useful researches that will make the people cope and adapt to the changing climate.

\section{Acknowledgements}

This paper was presented by the first and second authors at the $3^{\text {rd }}$ Bi-Annual SANORD International Conference held at the University of the Witwatersrand, Johannesburg, from 27 to 30 November 2011. The conference's theme was "Deepening Collaboration between Southern African and Nordic Higher Education for Shared Solutions to Research Capacity Development. The first and second authors would like to thank the participants for their useful comments when the paper was presented. The third author used substantial contemporary scholarly literature to heavily revise and enlarged the paper in order to make it robust and of high academic quality.

\section{References}

Access 2014. Applied Centre for Climate and Earth Sciences. About the Access Centre. From http://www.access.ac.za. (Retrieved on March 30, 2014).

Adetula V 2011. Measuring democracy and 'good governance'in Africa: A critique of assumptions and methods. From www.academia.edu/790041/Measuring_democracy_and_good_governancein. (Retrieved on April 26, 2013).

Adger WN 2003. Adaptation to climate change in the developing world. Progress in Development Studies, 3(3):179-195.

Adger WN, Huq S, Brown K, Conway D, Hulme M 2002. Adaptation to climate change: Setting the Agenda for Development Policy and Research. From http://www.start.org/projects/aiacc_project/meetings/norwich_02/norwich_cd/appendices/articles_vuln _adaptcap/adapt_climate_change.pdf. (Retrieved on March 4, 2012). 
Assessment ME 2005. Ecosystems and human well-being. From http://www.who.int/globalchange/ecosystems/ecosys.pdf. (Retrieved on May 20, 2012).

Ayisi KK 2012. Innovations and Technologies for Responding to Global Climate Change: The Role of the Risk and Vulnerability Assessment Center (RVAC), South Africa. From http://www.iowastatedaily.com/calendar/lectures/event_e0ea53a8-2cdc-11e2a9ff-001a4bcf887a.html. (Retrieved on February 18, 2014).

Barnett TP, Adam JC, Lettenmaier DP 2005. Potential impacts of a warming climate on water availability in snow-dominated regions. Nature Review, 438:303-309.

Beer J, McCracken K 2012. Cosmogenic radionuclides: theory and applications in the terrestrial and space environments. New York, USA: Springer publishers.

Black R, Kniveton D, Skeldon R, Coppard D, Murata A, Schmidt-Verkerk K 2008. Demographics and Climate Change: Future Trends And their Policy Implications for Migration. From http://r4d.dfid.gov.uk/PDF/Outputs/MigrationGlobPov/WP-T27.pdf. (Retrieved on May 11, 2012).

Brooks N 2003.Vulnerability, risk and adaptation: A conceptual framework. Norwich, UK: Tyndall Centre for Climate Change Research Publication.

Bryan E, Deressa TT, Gbetibouo GA, Ringler C 2009.Adaptation to climate change in Ethiopia and South Africa: options and constraints. Environmental Science \& Policy. 12(4): 413-426.

Chambers N, Simmons C, Wackernagel M 2014. Sharing nature's interest: ecological footprints as an indicator of sustainability. New York, USA: Routledge Publishers.

Chee YE 2004. An ecological perspective on the valuation of ecosystem services. Biological Conservation, 120(4): 549-565.

Cheng-Zhang Z, Limin H, Squires V 2010. Towards Sustainable Use of Rangelands in North-West China. From http://link.springer.com/book/10.1007/978-90-481-9622-7. (Retrieved on January 21, 2012).

Chevallier R 2011. Towards the climate change Summit in Durban: The role of the South African government as an agent of change in Africa. From http://www.open.ac.uk/socialsciences/bisa-africa/files/africanagency-seminar3-chevallier.pdf. (Retrieved on October 10, 2013)

Conway GR, Barbier EB 2013. After the green revolution: sustainable agriculture for development. London, UK: Earthscan Publication.

Cuff DJ 2001. Encyclopedia of global change: environmental change and human society. Oxford, UK: Oxford University Press.

Davies RAG, Midgley SJE, Chestermann S 2010. Climate Risk and Vulnerability Mapping for Southern Africa, Status Quo (2008) and Future (2050). Cape Town, South Africa: OneWorld Sustainable Investments (PTY) Ltd.

Davis CL 2011. Climate risk and vulnerability: a handbook for Southern Africa and Industrial Research. Pretoria, South Africa: Council for Scientific and Industrial Research publication.

Diao X, Hazell PBR, Resnick D, Thurlow J 2007. The role of agriculture in development: Implications for Sub-Saharan Africa. Washington, USA: International Food Policy Research Institute Publication.

DST 2010. South Africa's Department of Science and Technology (DST). South Africa Risk and Vulnerability Atlas. From http://www.rvatlas.org/download/chipping-2010.00901.pdf. (Retrieved on July 288, 2013).

Eagan R, Schofield TA 1997..Weather Wise!(eBook). Dayton, Ohio, USA: Teaching and Learning Company.

Eldredge N 2000. Life in the balance: humanity and the biodiversity crisis. New Jersey, USA: Niles Eldredge Publishers.

Few R, Brown K, Tompkins EL 2007. Public participation and climate change adaptation: avoiding the illusion of inclusion. Climate Policy, 7(1): 46-59.

Flannery T 2006. The weather makers: How man is changing the climate and what it means for life on earth. New York, USA: Grove Press.

Fraser EDG, Dougill AJ, Hubacek K, Quinn Claire H, Sendzimir J, Termansen M 2011. Assessing Vulnerability to Climate Change in Dryland Livelihood Systems: Conceptual Challenges and Interdisciplinary Solutions. Ecology \& Society, 16(3):1-12.

Hans-Martin F 2007. Vulnerability: A generally applicable conceptual framework for climate change research. Global Environmental Change, 17(2):155-167.

Hans-Martin F, Klein RJT 2006. Climate Change Vulnerability Assessments: An Evolution of Conceptual Thinking. Climatic Change, 75(3):301-329.

Hugé J, Waas T, Eggermont G, Verbruggen A 2011.Impact assessment for a sustainable energy future-Reflections and practical experiences. Energy Policy, 39(10): 6243-6253.

Huq S, Konate M 2003. Mainstreaming adaptation to climate change in least developed countries (LDCs). Nottingham, UK: Russell Press.

Islands C 2012. Joint National Action Plan for Disaster Risk Management Climate Change Adaptation (JNAP) 2011-2015. From http://www.undp-alm.org/sites/default/files/downloads/jnap_-_final_2012_cook_is.pdf. (Retrieved on June 1, 2013).

Kaplan D 2008. Science and Technology Policy in South Africa Past Performance and Proposals for the Future. Science Technology Society, 13(1): 95-122.

Karl TR, Trenberth KE 2003. Modern Global Climate Change. Science, 5(302): 1719-1723.

Kaygusuz K 2009. Energy and environmental issues relating to greenhouse gas emissions for sustainable development in Turkey. Renewable and Sustainable Energy Reviews, 13(1):253-270.

Kelly PM, Adger WN 2000. Theory and Practice in Assessing Vulnerability to Climate Change and Facilitating Adaptation. Climatic Change, 47(4):325-352.

Kent M 2011. Vegetation description and data analysis: a practical approach. Chichester, UK: John Wiley \& Sons. 
McGuigan C, Reynolds R, Wiedmer D 2002. Poverty and climate change: Assessing impacts in developing countries and the initiatives of the international community. From http://www.odi.org.uk/sites/odi.org.uk/files/odi-assets/publications-opinion-files/3449.pdf. (Retrieved on July 6, 2012).

Meffe G, Nielsen L, Knight RL, Schenborn D 2010. Ecosystem management: adaptive, community-based conservation. Washington, New York: Island Press.

Midgley GF, Thuiller W 2011. Potential responses of terrestrial biodiversity in Southern Africa to anthropogenic climate change. Regional Environmental Change, 11(1):127-135.

Moldan B, Janoušková S, Hák T 2012. How to understand and measure environmental sustainability: Indicators and targets. Ecological Indicators, 17: 4-13.

Mukheibir P, Ziervogel G 2007. Developing a Municipal Adaptation Plan (MAP) for climate change: the city of Cape Town. Environment and Urbanization, 19(1):143-158.

Munier N 2005. Introduction to Sustainability, Road to a Better Future. From http://link.springer.com/book/10.1007/1-4020-3558-6. (Retrieved on September 5, 2012).

Muys B 2013. Climate and Development (KLIMOS). From http://www.biw.kuleuven.be/lbh/lbnl/forecoman/klimos /klimosfrontpageEng.html. (Retrieved on May 8, 2014).

Nhemachena C, Hassan R 2007. Micro-level analysis of farmers adaption to climate change in Southern Africa. Washington, USA: International Food Policy Research Institute Publication.

Nunes PALD, van den Bergh JCJM 2001. Economic valuation of biodiversity: sense or nonsense? Ecological economics, 39(2):203222.

O'Keeffe B, Creamer C, Blair N, Driscoll J , Keaveney K 2009. Restructuring: Local Sustainable Solutions to the Rural Challenge. From http://dspace.mic.ul.ie/handle/10395/1402. (Retrieved on August 16, 2012).

Paterson A 2010. Launch of exciting new ventures in marine research. http://www.saeon.ac.za/enewsletter/archives/2010/april/doc01. (Retrieved July 9, 2013).

Pauw JC 2011.Combat Change with Change. Pretoria, South Africa: Published by South African Environmental Observation Network (SAEON).

Ribeiro M, Losenno C, Dworak T, Massey E, Swart R, Benzie M, Laaser C 2009. Design of guidelines for the elaboration of Regional Climate Change Adaptations Strategies. From http://www.ecologic.eu/files/attachments/Projects/1926/1926-ras-final-report.pdf. (Retrieved on July 4, 2013).

Roberts D 2008. Thinking globally, acting locally — institutionalizing climate change at the local government level in Durban, South Africa. Environment and Urbanization, 20(2):521-537.

SAEON 2009. South African Environmental Observation Network (SAEON). SAEON background. saeon background. From http://www.saeon.htm. (Retrieved on January 4, 2014).

SANROD 2013. Southern African-Nordic Centre (SANORD). Towards the end of the Millennium Development Goals Era: What contribution have our universities made? From http://www.crop.org/storypg.aspx?id=722\&MenuNode=633984655460004113 \&zone=41. (Retrieved on February 4, 2014).

Seely M, Dirkx E, Hager C, Klintenberg P, Roberts C, von Oertzen D 2008. Advances in desertification and climate change research: Are they accessible for application to enhance adaptive capacity? Global and Planetary Change, 64(3-4):236-243.

SAEON 2010. South African Environmental Observation Network (SEAON). SEON Background. From http://www.saeon.ac.za. (Retrieved November 14, 2013).

Shukla PR 2003. Climate change and India: Vulnerability assessment and adaptation. New Delhi, India: Baba Barkha Nath Press.

Smit B, Pilifosova O 2003. Adaptation to climate change in the context of sustainable development and equity. From https://www.vie.unu.edu/file/get/9995.pdf. (Retrieved on April 11, 2012).

Spellerberg IF 2005. Monitoring ecological change. Cambridge, UK: Cambridge University Press.

Stern N 2007. The economics of climate change: the Stern review. Cambridge, UK: Cambridge university Press.

Thomas AD, Hoon SR, Linton PE 2008. Carbon dioxide fluxes from cyanobacteria crusted soils in Kalahari. Applied Soil Ecology, 39: 254-263.

Turner BL, Lambin EF, Reenberg A 2007. The emergence of land change science for global environmental change and sustainability. From http://www.pnas.org/content/104/52/20666.full. (Retrieved on September 16, 2012).

Tyler SW, Selker JS, Hausner MB, Hatch CE, Torgersen T, Thodal CE, Schladow SG 2009. Environmental temperature sensing using Raman spectra DTS fiber-optic methods. From http://onlinelibrary.wiley.com/doi/10.1002/wrcr.v45.4/issuetoc. (Retrieved on June 6, 2012).

van Aalst MK, Cannon T, Burton L 2008. Community level adaptation to climate change: The potential role of participatory community risk assessment. Global Environmental Change, 18(1):165-179.

Van der Merwe C 2010. Kraak MJ, Ormeling F 2011. Cartography: visualization of spatial data. New York, USA: Guilford Publications, Incorporation.

Van Der Merwe C 2010. South African risk and vulnerability atlas launched. From http://www.polity.org.za/print-version/south-africanrisk-and-vulnerability. (Retrieved on April 4, 2013).

van Vuuren DP, Bouwman LF 2006. Exploring past and future changes in the ecological footprint for world regions. Ecological Economics, 52(1):43-62.

Vetter S 2009. Drought, change and resilience in South Africa's arid and semi-arid rangelands. South African Journal of Science, 105(1- 
2): 29-33.

Vogel C, Koch I, Van Zyl K 2010. A Persistent Truth"--Reflections on Drought Risk Management in Southern Africa. From http://eds.b.ebscohost.com/ehost/search/advanced?sid=255a306c-e21d-44a8-896717863b7fe76e\%40sessionmgr114\&vid=1\&hid=105. (Retrieved on January 4, 2012).

Wackernagel M, Rees WE 2013. Our ecological footprint: reducing human impact on the earth. Gabriola Island, Canada: New Society Press. 